\title{
TRAFALGAR (1805): POLÍTICA, LITERATURA Y MITO
}

\author{
Luis F. DÍAZ LARIOS \\ Universitat de Barcelona
}

\begin{abstract}
Aun sería tiempo de recoger, entre los viejos que se hallaron en aquel combate, tan siquiera una parte de los rasgos sublimes de valor que ofrecieron [...]. En el rincón del fuego, ellos los contarán a sus nietos y bisnietos, en quien debe resucitar ese gran pueblo generoso, trabajado tanto tiempo por los infortunios y el olvido.
\end{abstract}

Príncipe de la Paz, Memorias

El anciano don Antonio Alcalá Galiano culmina con la muerte de su padre el relato de los angustiosos días en que, siendo un adolescente, vivió desde su Cádiz natal la batalla de Trafalgar. Doblemente herido, sin querer abandonar el puente, el brigadier dirigía la maniobra del Bahama, del que era comandante, cuando una bala le segó la cabeza. «iTal fue el trágico fin de don Dionisio Alcalá Galiano, cuyas prendas y heroicidad no parecerá mal que recuerde un hijo ufano de serlo!», exclama don Antonio (1955, I, pág. 305a) quien, desde sus sentimientos filiales y su experiencia subjetiva, proyecta y realza la dimensión individual de una acción episódica en el plano objetivo de su marco histórico: la gran batalla que desde el primer momento alcanzó categoría de mito para ingleses y españoles y, en menor grado, franceses.

Aunque a lo largo del Setecientos -por ceñirme a la centuria inmediata- tuvieron lugar otros combates navales importantes entre los mismos contendientes y con resultados alternativos, ninguno ha dejado huella tan profunda en la conciencia colectiva. Es difícil encontrar, en efecto, una batalla del siglo XVIII que haya merecido hasta nuestros días tanta atención como la 
de Trafalgar'. No fueron ajenas a la pronta difusión de la noticia las mejoras técnicas de la imprenta y del grabado, que sin duda facilitaron la creación de la leyenda. La prensa informó del resultado enseguida, ilustrándolo en ocasiones con odas y elegías compuestas para la ocasión ${ }^{2}$, y muchas se publicaron en pliegos sueltos ${ }^{3}$, a veces con solo las iniciales de su autor ${ }^{4}$. Proliferaron las estampas alusivas que reproducían las estrategias, las refriegas y los retratos de los protagonistas más destacados de la jornada ${ }^{5}$. De las bellas artes, sobre todo la pintura fue la que dejó más constancia de su dedicación al tema. Y, en fin, los estudios históricos -militares, políticos, biográficos--, se sucedieron sin interrupción desde fechas muy próximas a los acontecimientos.

La explicación de este éxito no hay que buscarla solo en el valor de los contendientes y en haber sido el último combate librado con navios de línea. Estos aspectos son más o menos anecdóticos y no justifican un interés tan continuado. Porque la batalla que tuvo lugar a la vista del cabo de Trafalgar el 21 de octubre de 1805 es mucho más que una anécdota, y su dimensión bélica no debiera relegar su trascendencia política y trasfondo ideológico, que se trasluce en una poesía de circunstancias de dudosa perennidad, pero de indudable interés, en mi opinión, tanto por lo que dice como por lo que calla. En la complicada partida de ajedrez que jugaban las potencias sobre el tablero de Europa, el resultado del choque

'Recuérdense la popularísima serie novelesca de Patrick O'Brian o el «relato naval» Cabo Trafalgar que Arturo Pérez Reverte publicó en el pasado octubre, con toda oportunidad, y dos meses después llevaba cinco ediciones, aparte algún congreso programado para conmemorar la efeméride. Tengo que reconocer, sin embargo, que mis pesquisas sobre novelas anteriores a la de Pérez Galdós han sido infructuosas; en cuanto a teatro, sólo he encontrado una referencia: Los ayes de la viudezo la viuda de un marino muerto en el combate naval de 21 de octubre de 1805. Soliloquio trágico con musica en sus intervalos (Lafarga 1991, pág. 173).

2 The Times de Londres (7 de noviembre) publicaba en su pimera página con grandes titulares: «Battle of Trafalgar. Capture of French and Spanish fleets. Death of Nelson. List of Killed and Wounded). La prensa de los derrotados - Le Moniteur de Paris, la Gazeta de Madrid, el Diario de Barcelona- dio la noticia limitándose a los partes oficiales. En el Memorial Literario aparecieron extractos y reseñas de las composiciones dedicadas al combate.

${ }^{3}$ Es el caso de la oda de María Rosa de Gálvez En elogio de la Marina Española, Madrid, Imprenta de Repullés, 1806 (Bordiga Grinstein 2003, págs. 176-182).

${ }^{4}$ Como la Relación en la que se elogia sencillamente a los Héroes del combate el día 12 [sic] de octubre, sostenido por la Escuadra Combatiente contra la inglesa, mandada por el almirante Nelson. Escrita en verso octosilabo. P. C. T. C. R. Barcelona. Por la Viuda Aguas Vivas y los Consortes Garriga. Año de 1806 (Marco 1977, II, pág. 515).

${ }^{5}$ En los museos National Maritime (Londres y Greewich), de la Marine (Paris) y Naval y la Biblioteca Nacional (Madrid) se encuentran las más importantes colecciones.

"Baste recordar los cuadros de auténticos especialistas, como los ingleses N. Pocock, J.M.W. Turner, W.J. Huggins, A.W. Devis, H. Wyllie, el francés A. Mayer y, entre los españoles, J.R. Luna, R. Monleón y J. Sans y Cabot. Sin olvidar las muchas estatuas dedicadas a los héroes, cuyas figuras decoran plazas públicas o prestan sus nombres a los callejeros urbanos. 
naval a toca penoles que contemplaron los gaditanos desde sus casas fue decisivo para el bonapartismo, libró a Inglaterra del peligro de una invasión afirmando su hegemonía marítima, y liquidó el poderío naval español, haciéndole imposible más tarde defender su imperio americano. En otro orden de cosas, las circunstancias que concurrieron en la derrota de la escuadra aliada pusieron en evidencia la subordinación de los intereses de España a los de Napoleón, e intensificó el rechazo que amplios sectores sociales sentían hacia Godoy, señalado como el principal causante de la desgracia nacional, pues el resultado (Chastenet 1972; Seco Serrano 1978) fue interpretado por algunos -entre quienes se encontraban Quintana y sus amigos- como el trágico final de un largo período esperanzador y regeneracionista.

La paz de Amiens (25 de marzo de 1802) solo supuso una tregua entre Francia e Inglaterra - «experimental peace» la llamó Jorge III- porque no se estableció sobre bases sólidas. Para España, a pesar del trato poco favorable que recibió de su aliada, representó un respiro para atender a su maltrecha economía y reponer las pérdidas navales que le ocasionó su apoyo a la escuadra francesa. La escasez de subsistencias por la interrupción del comercio, las malas cosechas y el brote de la peste alejaban a Godoy de la tentación de aliarse nuevamente con Napoleón a pesar de las presiones de éste; pero también desconfiaba de las del gobierno inglés para asegurarse la neutralidad española. Ambas acciones sobre el Príncipe de la $\mathrm{Paz}$-arbitro de la situación en los meses previos a la reanudación de la guerra, en tanto que Madrid se convertía en campo de batalla diplomática- tenían por principal objeto los navíos españoles: contar con ellos en un caso, evitar en otro su colaboración con el enemigo. Godoy, al fracasar su proyecto de establecer una alianza con Prusia y Rusia para mantener a España equidistante de las potencias rivales (Schop Soler 1971) y al estallar de nuevo el conflicto en mayo de 1803, se encontrarrá otra vez entre el fuego cruzado de Pitt y Napoleón, «náufrago y no piloto en la tormenta», dicho con la expresiva frase de Jesús Pabón (1944, pág. 156). La dificultad de mantener la neutralidad aumentaba ahora al enredarse con las decisiones de política exterior los conflictos internos y personales. Por un lado, el Emperador exigía el cumplimiento del tratado de subsidios, firmado en París en octubre y en cierto modo concreción de aspectos recogidos en el de San Ildefonso (agosto de 1796), por el que España se comprometía a pagar a Francia veinticuatro millones de reales mensuales para evitar la declaración de guerra a Inglaterra, lo que lógicamente no podía dejar indiferente al gobierno británico, que en repetidas ocasiones exigió explicaciones cada vez más amenazadoras al español. Por otro, la insegura posición interna del favorito, enfrentado al naciente partido fernandino, pro inglés y amenazando con desposeerle del poder a la primera oportunidad, no le daba demasiadas opciones de maniobra. Ello explica «el radical cambio de actitud [...] adoptado por Godoy desde 1804» (Seco Serrano 
1978, pág. 144) sometiendo a su propio interés y a la política hegemónica del Imperio la de su país.

Para vencer a su principal rival, Napoleón había ideado el ambicioso plan de invadir la Gran Bretaña, trasladando la guerra terrestre a las islas. Para ello concentró un poderoso ejército en Boulogne-sur-Mer. El punto más débil y arriesgado del proyecto consistía en contrarrestar el poderío naval inglés, para lo que la marina francesa no se bastaba. Una vez más, pues, era imprescindible contar con los aliados haciendo valer los tratados de mutua ayuda. España pasaba así de neutral a no beligerante, incómodo status que ponía los puertos y barcos españoles en el punto de mira de los «cruceros» ingleses, que con sus hostigamientos forzaron finalmente la declaración de guerra de Carlos IV.

Aunque no el único, el incidente del 5 de octubre de 1804 (Marliani 1850, Apéndices; Ferrer de Couto 1851, págs. 83-89) fue el que soliviantó más los ánimos, dando lugar a un creciente clamor hostil y revanchista contra los ingleses, que sin duda favorecía al gobierno. La carga emocional con que se vivieron los preliminares que desembocaron en Trafalgar explica, al menos en parte, la reacción tras la derrota. En ese episodio se inspiró Juan María Maury para componer las 67 octavas de La agresión británica, un canto «trompeteador, vago y de un color parduzco», como lo descalifica Cejador, justamente inmisericorde (1972, VI, pág. 324). Desde un punto de vista estilístico carece de interés: es una muestra epigonal de la épica dieciochesca. Por lo que importa recordarlo aquí es justamente por su carácter circunstancial, puesto que parece responder a una sugestión propagandística, la que convenía difundir al Generalisimo para justificar el viraje de su política a favor de la napoleónica, convirtiendo ésta y otras provocaciones en casus belli.

Las primeras estrofas celebran la efímera paz de Amiens, a cuyo goce se entregan las naciones, y enseguida amenazada por las ambiciones de un sector belicista:

Ya la facción reinante en Inglaterra

$[\ldots]$ los planes encierra

en que estragos y lloro al mundo envía.

(pág. 488b)

Es decir, Pitt y sus partidarios, que imponen sus criterios a quienes en su propio país conservan el respeto a los principios del «antiguo honor». Son, pues, la ambición y la codicia de unos pocos las que, rompiendo la armonía general, decidirán la agresión a cuatro fragatas españolas que, ajenas al peligro, se acercan a Cádiz con una millonaria recaudación de pesos fuertes americanos. Interceptadas por una flotilla inglesa, su tripulación prefirió defenderse antes que entregarse, esgrimiendo el derecho a navegar libremente en tiempos de paz. La fatalidad hizo que estallara el barco en que viajaba la familia del segundo jefe de la expedición, 
don Diego de Alvear. El poeta describe la patética escena y no puede ocultar su dolor por la suerte de las víctimas que ha ocasionado la «traición cobarde», pero inmediatamente vaticina el desquite:

¡Victoria infame, que en amargo duelo

convertirán con vengadora furia

los que lloraron la alevosa injuria!

(Ibid.)

Sospecho que el poema terminaría con unas octavas distintas de las que han llegado hasta nosotros; pero publicado en 1806, quizás aprovechando el éxito literario de la batalla de Trafalgar, su primitivo final no respondía ya a las expectativas y emociones del momento. Creo que eso podría explicar las confusas cuatro últimas estrofas, en que los genios de la guerra y del mar auguran la «venganza» en «nuevas lides»:

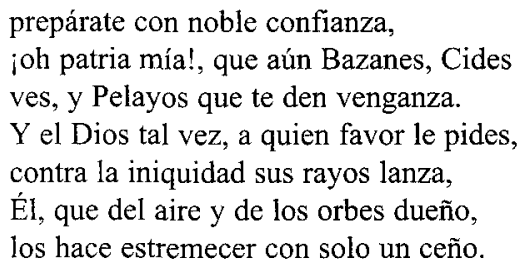

(pág. 490b).

¿A qué venganza se refiere si acaba de ocurrir el desastre naval del 21 de octubre? Parece una vaguedad intencionada que el lector puede interpretar a su capricho. Desde la perspectiva de 1804, las «nuevas lides» pueden sugerir la inmediata intervención española al lado de Francia, justificándola por razones propias como respuesta a la agresión que había injuriado el honor y colmado la paciencia de los españoles. De hecho, el gobierno de Godoy caldeó los ánimos, publicando en la Gazeta de Madrid a mediados de diciembre un manifiesto patriótico e incendiario antibritánico días antes de declarar formalmente la guerra a Inglaterra (Godoy 1956, II, págs. 37 y ss.; Schop Soler 1971, págs. 121 y ss.). Ahora bien, considerado desde la fecha de su publicación, cuando ya había ocurrido la batalla tan brillantemente resuelta por Nelson y que dejaba en evidencia al Príncipe de la Paz ante la opinión pública, el poema de Maury era un recordatorio dirigido a los olvidadizos sobre quiénes habían empezado las hostilidades. Los versos:

[...] no las fuentes del valor se agotan, que héroes sin cuento las cenizas brotan,

(Ibid.)

no eran simplemente la ripiosa rúbrica de una octava, sino el mensaje esperanzador de que este y otros ataques de adversa fortuna solo eran episodios de una 
guerra aún inacabada. Se trataba de infundir optimismo en medio de los reveses, aplacar los ánimos y reforzar el fervor patriótico distrayendo de la cruda realidad. Esta maniobra, al achacar al «implacable genio» del destino los desastres bélicos, permitía elogiar el valor, heroísmo y honor de las víctimas, y desviaba la atención de los responsables de una política errada. Similar manipulación emplearían también algunos poetas al lamentar la derrota del año siguiente.

Tampoco fue éste el último incidente: provocaciones parecidas continuaron hasta el choque definitivo. El 19 de noviembre el capitán del Donnegal «mandó romper el fuego en los momentos de estarse comunicando amistosamente con el de nuestra fragata [...], el cual perdió la vida en aquel desigual combate» (Ferrer de Couto 1851, pág. 88). La acción del navio inglés inspiró a Eugenio de Tapia una indignada «A la muerte de Don Josef Valera, Comandante de la Fragata Anfitrite», y publicada al año siguiente en Variedades de Ciencias, Literatura y Artes. Su editor reciente acierta al afirmar que «este poema de Tapia es un documento importante como expresión del ambiente tan ferozmente antibritánico del período inmediatamente antes de la batalla de Trafalgar [...]» (Quirk 1999, pág. 134).

Ratificada la alianza franco-española en enero de 1805, todavía consigue Napoleón la firma de una convención marítima que subordinara la escuadra española a la francesa. Sabidas son las singladuras del azaroso viaje atlántico de los barcos mandados por Villeneuve, perseguidos por Nelson hasta bloquearlos en Cádiz; la irritación de Bonaparte ante la indecisión de su almirante para dar el golpe definitivo; la desconfianza de los marinos españoles; la pasividad de Godoy, incapaz de proponer al Emperador la jefatura de Gravina, a pesar de los indiscutibles avales y de los informes del teniente general, al que no obstante insta a seguir obedeciendo a Villeneuve, cuyo relevo por Rosily era ya inminente; la imprudente orden de éste de salir del puerto para desmentir las acusaciones de cobardía que empezaban a cundir... Todo, visto desde la distancia, se presenta como la crónica de una derrota anunciada. Y, llegada ésta, a tenor de la variada documentación que se conserva, desde crónicas periodísticas hasta memorias y epistolarios pasando por informes de protagonistas y espectadores, parece que la opinión pœblica no reaccionó de modo tan unánime como se ha afirmado, sino con una mezcla de dolor, orgullo herido, despecho y recelo, a veces solo apuntado, según muestran las cartas de la reina María Luisa dirigidas al favorito (Seco Serrano 1978, págs. 162-163).

Pues bien, limitándonos solo a los poemas circunstanciales más asequibles, se observa igualmente una diversidad de actitudes que manifiestan, cualquiera que sea el punto de vista, la toma de conciencia de sus autores ante la crisis. Y, por los datos que conocemos, podemos añadir que fueron leídos con gran interés por sus contemporáneos de todos los estamentos. El hecho de que muchos apa- 
recieran en las páginas de la Minerva y del Memorial Literario acompañados de comentarios controvertidos (Dérozier 1978, págs. 253-254, n. 181) demuestra el apasionamiento con que los ilustrados recibieron estos enardecidos versos. Por las apuntaciones de sus Diarios, conocemos con exactitud cuándo leyó el «prisionero de Bellvery La tempestad y la guerra de Arriaza, La sombra de Nelson de Moratín y las odas de Sánchez Barbero (Jovellanos 1956, IV, págs. 81a y 89). Godoy los elogiaba, bastantes años después en sus Memorias, como expresión de «la conformidad de sentimientos y opiniones entre los pueblos y el Gobierno» (1956, II, pág. 63). Pero también encontraron buena acogida en niveles populares según se deduce de su publicación en pliegos sueltos?.

Tan buena recepción respondía más que a consideraciones estéticas -que desde luego fueron muy tenidas en cuenta por los críticos-, a razones emocionales e ideológicas. Cualquiera que fuera su logro artístico, los versos escritos para la ocasión combinaban también el sentimiento con la poesía, el arte con el mensaje. Porque se trataba de composiciones de pie forzado, con el tratamiento obligado de unos motivos fijos, son significativos los elementos de libre invención o elección, que determinan el sentido último del texto y explicitan los compromisos íntimos del poeta ${ }^{8}$. En ese sentido me parece útil comparar las aportaciones al tema de la 'batalla de Trafalgar' más célebres de su tiempo.

Moratín, Quintana, Mor de Fuentes, Arriaza y Sánchez Barbero revelan en sus respectivas obras un tono similar, grave y melancólico. Los cinco comparten y escriben a impulsos de un sentimiento patriótico, pero difieren en su concepción. Conviene insistir también en la intención que se advierte en los propios títulos. En tanto Mor, Arriaza y Sánchez subrayan su interés por la batalla misma, Quintana pone el acentos en los héroes y Moratín en el enemigo. Tal diferencia de enfoque parece responder a actitudes políticas distintas e irreconciliables.

En La sombra de Nelson de Inarco Celonio (1844, pág. 610a), la aparición espectral del «adalid britano» tras la batalla en donde ha encontrado la muerte tiene como fin vaticinar la futura derrota de Albión por Napoleón, con quien «inflamada/en belicoso ardor la fuerte Hesperia» se ha aliado. Moratín no dedica

' Aparte el ejemplo citado arriba (cf. notas 3 y 4), recuérdense también la oda de Quintana, aparecida suelta (Madrid, lmp. Real, 1805) antes de ser recogida en Poesias (Madrid, Imp. Nacional, 1813), y El combate naval del 21 de octubre de Mor de Fuentes (Madrid, Cano, 1805; y Barcelona, Vda. de Aiguasvivas y los consortes Garriga, 1805) quien, según cuenta en su Bosquejillo, «se repitió hasta tercera edición, y me lo reimprimieron también al mismo tiempo en Cartagena y en Cádiz, y aun no sé si en algunas partes de América» (1957, In pág. 383a).

* Me parece tan obvia que casi no sería necesario señalarla, la relación entre métrica y público al que se dirige el poeta, que condiciona también el tono y la dicción. Las preferencias por el romance, por ejemplo, apuntan a un lector popular con más certeza que el medio usado. La Relación citada arriba, «escrita en verso octosílabo», no creo que interesara al mismo público que la oda de Quintana, aunque ambas se publicaran en sendos pliegos. 
al desastre naval más de quince versos, dejando en penumbra el resultado. En cambio, en la última parte exhorta al rey para reanudar la guerra y satisfacer a quienes la reclaman:
Carlos, la tierra que a tu pie se humilla
pide venganza. Cumple los deseos
de los que imploran tu favor y esperan
en nuevas lides, combatiendo audaces,
castigar al soberbio que tu nombre
no reverencie y tu poder insulte...
Arma su diestra y te darán victorias.

(pág. 610a)

De este modo, muerto Nelson, lo que permanece es la alianza franco-española representada por sus monarcas. El pro bonapartismo y, en última instancia, la identificación aduladora con la política exterior de Godoy son transparentes. Es curioso lo que Jovellanos escribe el 14 de mayo de 1806 en el Diario: «Por la noche conversación hasta la partida. Item se leyó La sombra de Nelson, en tonto» (1956, IV, pág. 89a). Sin arriesgar conclusiones, me sorprende que únicamente el poema de Moratín mereciera un comentario, escueto pero elocuente, entre todos los que sobre el mismo asunto leyó por esos días. Cabe suponer que a don Melchor no le harían gracia las adulaciones dirigidas al rey que causaba su desgracia, ni los aplausos a la política de Godoy, de quien se había distanciado hacía tiempo (Seco Serrano 1963, págs. 238-266).

La Oda a los marinos españoles en el combate del 21 de octubre, retitulada Al combate de Trafalgar (Quintana 1969, págs. 294-300), como se la conoce hoy perdiendo en parte su sentido, corresponde a otro compromiso. Tras la reflexión inicial sobre la constancia como principio moral en que debe asentarse la conducta de los pueblos por encima de las contingencias, Quintana se adentra en el tema evocando el secuestro de las fragatas, en alusión al asunto tratado por Maury. Esta acción traidora en tiempos de paz justifica la ira y el santo ardor de los españoles contra los ingleses. Las siguientes silvas realzan en el plano moral el enfrentamiento que se produce en el mar: a la rapacidad y la alevosia británicas y a la soberbia y presunción de Nelson, oponen los marinos españoles las virtudes de valor, sabiduría y justicia. Por contra, los barcos ingleses doblan en número a los españoles. La victoria de aquellos es inevitable por su ventaja material, pero a costa de la muerte de Nelson, presentada como castigo moral («ejemplo grande a la arrogancia humana», v. 157) y compensación por las pérdidas españolas («digno holocausto a la aflicción hispana», v. 158). Sin embargo, el llanto por éstas no impide al poeta expresar noblemente su respeto al enemigo: «inglés te aborrecí, y héroe te admiro» (v. 150). 
Me parece muy importante señalar el tratamiento que tiene el motivo de la muerte en esas estrofas centrales (vv. 113-158) o, más precisamente, el panegírico funerario que vertebra esta innovadora $o d a^{9}$, súbitamente convertida en planto:

[...] Viuda la patria

de tantos héroes que enlutada llora, pide a su corazón lágrimas nuevas que a vuestro acerbo fin derrame ahora.

(vv. 126-129)

Porque con la desaparición de tan ilustres marinos, España no solo perdía buenos militares dignos de los «lauros de Marte» (v. 121), sino científicos en tiempos de paz que el hado no había perdonado («¿Cómo a aplacarle/ la oliva no bastó que unió Minerva...» (vv. 119-120). Alcalá Galiano, Churruca, Moyna, Castaños representaban el nuevo modelo de héroe ilustrado, aquel que pone sus virtudes a disposición de la patria, consciente de su responsabilidad cívica, aunque le lleve a sufrir sinsabores e incluso la muerte (Cattaneo 1971, pág. 60). Quintana los ha identificado con el hombre de bien que unos años antes había descrito Cadalso en sus Cartas marruecas 70 y 71 ; pero tras el tono elegíaco de estos versos, reorienta su poema hacia la oda y vuelve los ojos a la vida y al futuro: aún quedan Gravina -vivo aún cuando el autor componía sus versos-, Escaño, Álava y Cisneros:

y otros ciento alli están, firme coluna,

la dulce esperanza a nuestro patrio suelo

(vv. 197-198)

Más cerca de Quintana que de Moratín cabría situar las composiciones de Mor de Fuentes, Arriaza y Sánchez Barbero. El combate naval del 21 de octubre es un canto épico aunque Mor lo denomine silva, quizá porque era consciente de que, al realzar la dimensión humanística del héroe, transformaba el epos convencional. El autor se atiene a la habitual estructura Nombre + epiteto para referirse a los esforzados marinos, pero el adjetivo subraya siempre las virtudes intelectuales:

Mi numen volador contempla ufano

el impetuoso incontrastable esfuerzo

del culto, el noble, el inmortal Gravina,

de Álava audaz la activa inteligencia,

del gran Cisneros el tesón sereno,

"Su originalidad y mérito fueron reconocidos por sus contemporáneos, que la destacaron de las demás composiciones publicadas para la ocasión. J. N. Gallego, por ejemplo, dedicó el significativo soneto A Quintana, por su oda al combate de Trafalgar, en que equiparaba a los héroes y al poeta que los inmortalizaba. (1953, III, 413b). 


\section{y el espíritu ameno}

de Escaño, que hermanó la escelsa ciencia con el afán de su carrera heroica.

(pág. 5)

En cuanto a los textos de Arriaza - La tempestad y la guerra o el combate de Trafalgar, 1953, III, págs. 66 y 67-y Sánchez Barbero-Odas a la batalla de Trafalgar, 1952, II, págs. 564-567-, es muy probable que se escribieran bajo la sugestión de la oda de Quintana, de la que, sobre todo en el primero, procede el motivo de la constancia ( «iOh constancia! ¡Oh del alma ardiente brío!», 1953, III, pág. 66b), la invocación a la diosa de la Razón («Minerva, joh! salva al que en mejor fortuna [...]», pág. 67b), la insistencia en los mismos vicios achacados a los ingleses... Me parece muy elocuente que, salvo Moratín y Arriaza, quien sólo la alude («Rinda al león y al águila Neptuno», ibíd.), ninguno aluda a los franceses, como si quisieran borrar cualquier vestigio de una alianza catastrófica. Los tres sugieren una vaga ejemplaridad en la muerte de Nelson, presentada por Sánchez Barbero con una hostilidad que mereció el rechazo de sus mismos contemporáneos. $Y$ todos coinciden en el sentimiento de dolor por la derrota y la pérdida de tantas vidas humanas -que en Sánchez adquiere caracteres de denuncia universal contra la guerra--, y en el voluntarioso manifiesto final de esperanza en un triunfo futuro, que no llega a ocultar el sentimiento de frustración ante la evidencia de la batalla perdida.

Las variantes advertidas en los elementos recurrentes de la estructura superficial de estas composiciones parecen expresar las existentes en niveles más profundos, que remiten a su vez al enfrentamiento ideológico y estético entre Moratín y sus amigos -amparados por Godoy- y Quintana y los suyos, constituidos en oposición al favorito. Los compromisos políticos de ambos grupos ante la crisis de 1808 parecen apoyar la tesis de que la batalla de Trafalgar es uno de los hitos que señalan los distintos itinerarios seguidos por los ilustrados españoles en la encrucijada de entre siglos.

Como la derrota naval de 1898 , la de 1805 fue una dolorosa catarsis que puso en evidencia la debilidad y las contradicciones internas de un régimen político que tenía los días contados. Reforzó en un grupo de disidentes la convicción de impulsar un talante regenerador y revolucionario que estallaría en marzo de 1808 y animaría después las cortes de Cádiz. Inspiró, en finn, una poesía de circunstancias que reflejaba las divergencias partidistas de una Ilustración en crisis y atisbaba también, en algunos casos, un nuevo modelo de escribir. Casi era inevitable que años después, al proyectar Pérez Galdós la historia novelada de su siglo para explicar a sus contemporáneos el presente, empezara por Trafalgar. 


\section{BIBLIOGRAFÍA}

AA. VV., 1952-1953. Poetas líricos del siglo XVIII, Leopoldo Augusto DE CUeTo (ed.), Madrid, Atlas (B.A.E., 61, 63 y 67), vols. II y III.

Alcalá Galiano, Antonio, 1955. Memorias, en Obras escogidas de Don [...], Jorge CAMPOS (ed.), Madrid, Atlas (B.A.E., 83).

Bordiga Grinstern, Julia, 2003. La rosa trágica de Málaga: Vida y obra de Maria Rosa de Gálvez, Charlottesville, The University of Virginia (Anejos de Dieciocho 3), págs. 45, 58-59 y «Apéndice C: Obras», págs. 76-182.

Cattaneo, Maria Teresa, 1971. M. J. Quintana e R. del Valle Inclán, Milano, Cisalpino-La Goliardica.

CEJAdor, Julio, 1972. Historia de la lengua y literatura castellana, Madrid, Gredos, (ed. facs.).

Chastenet, Jacques, 1972. Godoy: Master of Spain 1792-1808, New Cork/ London, Kenniat Press.

DÉrozIER, Albert, 1978. Quintana y el nacimiento del liberalismo en España, Madrid, Turner.

Fernández de Moratín, Leandro, 1844. Obras de Don Nicolás [...] y de Don [...], Buenaventura Carlos ARIBAU (ed.), Madrid, Rivadeneyra (B.A.E., 2). FERRER DE COUTO, José, 1851. Historia del combate naval de Trafalgar, Madrid, Imprenta de W. Ayguals de Izco.

Godoy, Manuel, 1956. Memorias del Príncipe de la Paz, Carlos Seco Serrano (ed.), Madrid, Atlas (B.A.E., 89).

Harbron, John D., 1988. Trafalgar and the Spanish Navy, Anápolis, Md., Naval Institute Press.

HowarTH, David, 1969. Trafalgar. The Nelson Touch, London, Collins.

Illie, Paul, 1995-1996. The Age of Minerva, Philadelphia, University of Pennsylvania Press, 3 vols.

LAfArgA, Francisco, 1991. «Teatro político español (1805-1840): ensayo de un catálogo», en AA. VV., Teatro político espagnolo del primo Ottocento, Ermanno CALDERA (ed.), Roma, Bulzoni, págs. 167-251.

LON ROMEO, E, 1950. Trafalgar, Institución Fernando el Católico, Zaragoza. MAINE, René, 1955. Trafalgar. Le Waterloo naval de Napoléon, Paris, Hachettc. MARCO, Joaquín, 1977. Literatura popular en España en los siglos XVIII y XIX, Madrid, Taurus, 2 vols.

Marliani, Manuel, 1850. El combate de Trafalgar: Vindicación de la Armada española contra las aserciones injuriosas vertidas por $M$. Thiers en su historia del Consulado y del Imperio, Madrid, Matute.

MAury, Juan María, 1854. La agresión británica, en Poemas épicos, Carlos Rosell (ed.), Madrid, Ribadeneyra (B.A.E., 29), II, págs. 487-490. 
Mor De Fuentes, José, 1805. El combate naval del 21 de Octubre. Por Don [...]. Madrid por Cano [...], 23 págs.

- 1957. Bosquejillo de la vida y escritos de don [...] delineado por él mismo, en AA. VV. Memorias de tiempos de Fernando VII, Manuel ARTOLA (ed.), Madrid, Atlas (B.A.E., 97), I, págs. 373-428.

PABÓN, Jesús, 1944. Las ideas y el sistema napoleónicos, Madrid, Instituto de Estudios políticos.

QUIRK, Ronald J., 1999. «Una elegía inédita de Eugenio de Tapia 'A la muerte de Don Josef Varela' (1805)», Dieciocho, 22.1, págs. 133-138.

SCHOP SOLER, Ana María, 1971. Las relaciones entre España y Rusia en la época de Carlos $I V$, Universidad de Barcelona (Publicaciones de la Cátedra de Historia general de España).

SeCo Serrano, Carlos, 1963. «Godoy y Jovellanos», Archivum, 12, págs. 238266.

- 1978. Godoy, el hombre y el politico, Madrid, Espasa-Calpe (Selecciones Austral, 34).

- 1988. «Política exterior de Carlos IV», en José María Jover (dtor.), Historia de España dirigida por Menéndez Pidal. La época de la Ilustración (II), Madrid, Espasa-Calpe, vol. XXXI, págs. 658 y ss. 